will, however, be found so easy of application in this situation, or likely to answer the purpose so well, as the common interrupted suture.

I cannot but agree with Dr. Zeis, of Dresden, who, in his " Manual of Plastic Surgery," published at Dresden, in 1838, is desirous of impressing upon the surgeon's mind the neeessity of introducing a suture wherever the parts are not in accurate contact, and dissuading him from any limit as to the number he should apply. For the formation of the septum from the lip we are indebted to Dr. Dieffenbach and Mr. Liston, a method possessing many recommendations over that practised by the earlier operators, of forming the septum from the forehead. In the present instance many advantages were gained by adopting the proceeding of the last-named authority, among which the removal of the large cicatrix from the lip, formed by the arsenical preparation previously alluded to, was perhaps the most prominent.

As the healing process progressed the point of the new nose became much depressed, a circumstance of not unfrequent occurrence, I believe, during cicatrisation. No method of dressing that $I$ adopted prevented this, and by the time that the introduction of the flap was agreed upon, partly from the remains of the old nose, and partly from this contraction, the aperture of the nares was completely blocked up; some of the remains of the old nose, however, were readily removed, and the point was brought forward, by adopting a proceeding employed by $\mathrm{Mr}$. Fergusson, in a case given in his "System of Practical Surgery," p. 453, which is a kind of subcutaneous dissection of the cheeks from the superior maxilla, that enabled me to bring forward the apex, and keep it in that position by the introduction of the septum.

$\Delta t$ no period of his cure did this man refer the sensations produced by touching the new nose to his forehead; at one time, on the left ala being irritated with a pen, the painful feelings thus produced were referred to the right side of the feature. This has, however, gradually disappeared. The senses of smell and taste, which he had entirely lost during his illness, have been regained since his cure. Although there is no pretence to any novelty in the proceeding adopted in this case, there are still many points of interest connected with these operations, and the relief which they afford to the patient is a matter of much gratification to the surgeon and an honour to the art. Many individuals left to endure all the misery of wounded feelings, and (as in the present in. stance) the loss of the means of support, have been thus made comparatively happy, and $I$ cannot but express my surprise at finding an eminent modern authority describe the result of such an operation as " more curi. ous than useful," and declaring that " the substitute is more disagreeable than the deficiency."

\section{ON \\ ANNUAL VITAL PERIODS, BEING A FIFTH CONTRIBUTION TO VITAL PROLEPTICS.}

By T. LaYcock, M.D., Physician to the York Dispensary.

IN my last communication (page 826 , vol. ii., 1842-43)* I referred to the pathological influence of the seasons, and compared certain meteorological changes with pathological data. I wish now to state distinctly that I do not consider this the only or the best mode of attaining to a knowledge of the influence of the seasons on vital action. Our researches should be founded on physiology rather than on pathology; we must ascertain the annual cycle of normal action before we can correctly lay down that of pathological phenomena.

We know that quotidian vital periods are regulated by what may be termed the habit of recurrence, as well as by meteorological influences. A tendency to the performance of a physiological act, done at a given hour in one day, occurs at the same hour on the next. This is a fact I should suppose known to and observed by every one. Now, there is really the same tendency to the recurrence of annual periods, although it has not been so ex tensively noticed. The migrations of animals present some curious illustrations of this fact. The exact punctuality with which the storks return to their summer quarters at Smyrua is noticed by Mr. Hamilton (Researches in Asia Minor, vol. i., p. 70) as a curious fact; they generally appear on the 9th of March. "On my way to the fort of Aziz Khan, the Hazara manager of the district for Dost Mahomed," writes Mr. Moorcroft, "I passed a small pond filled by a stream from a holy spring, which was so full of trout as to baffle description or credibility. They were held sacred, and were exceedingly tame. On the 21 st of March to a day, according to the report of the people, the fish desert the pond for the rivulet that waters the valley." (Moorcroft's Travels, edited by Professor Wilson, vol. ii., p. 382.)

The dates of the reappearance and departure of migratory birds which visit us, correspond very closely year after year. Swifts, for example, are nearly all gone by the 10 th of August. The recurrence of disease at exactly annual periods has been noticed by various writers, and instances have been

* For the four preceding papers of Dr. Laycock, see LANCET, vol, ii., 1842-13, pages $124,160,423,029$. 
communicated to myself, the correctness of which I had no reason to doubt.

What is the cause of these periodic move. ments? Is it exoteric or esoteric? That is to say, do they occur only in virtue of periodic meteorological changes, or in consequence of a cycle of changes within the animal? Facts, I think, will show that the cause is exclusively neither the one or the other, but both, and compounded of both, that is to say, that it is esoteric and exoteric. The migration of animals is invariably connected with the commencement or cessation of the reproductive process, and in birds at least, according to Dr. Jenner (Phil. Trans., $1824, p .11$ ) as invariably connected with the size of the ovaria and testes; when these begin to shrink the birds are off, as the cuckoo, whose ovaria are atrophied in July. Certain changes take place in animals concurrently with the migratory movements and with the development and atrophy of the organs last mentioned, which have an important bearing on pathology. The most striking of these in birds are the growth of the sexual plumage, the fall of this, or moulting, and its regeneration; but there are other organs which are affected concurrently and in close connection with the ovaria and testes. As I have demonstrated these at length in my published work (A. Treatise on the Nervous Diseases of Women, chap. 2), I need not go over the ground again. The organs or structures under the influence of the ovaria and testes, are the thoracic region in the male, and the pelvic in the female, and the whole of the cutaneous products in both sexes, though for the most part negatively in the female. Thus, the colour of certain cutaneous appendages in butterfies, beetles, and fishes, is deeper in the male than the female, or is seen solely in the former. This fact is very conspicuous in the polygo. matus, a lepidopterous genus. It is also illustrated by the common stickleback, the grayling, and the bull-trout.

In all birds the sexual tints are observable: in the pye tribe not particularly striking, but in humming-birds (the butterflies of aves), and in birds of paradise, the cock bird displays a most extraordinary brilliancy of colour, far beyond that of the hen. The odoriferous glands of the skin are influenced by the ovaria or testes in probably all classes of animals; certainly in insects, reptiles, birds, and mammals. In the latter class these glands are situate, for the most part, on the lateral thoracic or inguinal region, or upon or close to the pudenda. The form and grouping of certain cutaneous appendages are materially induenced by the testes. In birds it is the feathers, \&c. of the two ends of the trunk, as the crest, wattles, neck and tail-feathers; in mammals the horns, mane, tusks (canine teeth), and general distribu. tion of the hair. The tufts on the ears of lynxes and squirrels appear only at the breeding season. In man the hair on the shoulders, as well as on the chest and throat, is influenced by the testes, and also (in the absence of hair) the sebaceous glands. On the contrary, in females, the cutaneous appendages of the face are not developed, but the subtegumentary fat is, and the mam. mary glands attain a magnitude never seen in males unless the function or structure of the testes be deranged.

The difference in size between the tho. racic and pelvic or abdominal regions is marked, with only two exceptions, in all the divisions of the animal kingdom, insects, fishes, birds, mammals. The neck, jaws, and appendages to the jaws, are also more strongly developed in males than females. The organs of voice are also influerced in a most remarkable manner by the testes. The females of insects are invariably silent, and, during incubation at least, the cock-bird is alone vocal. The voice of male mammals, as the ram, stallion, bull, the lion, and man himself, is well known to be altogether dif. ferent from that of the female, and to be in close dependance on the testes. In females the salivary glands, thyroid body, pharynx, fauces, and oesophagus, are all influenced indirectly, and in geueral, pathologically, by the ovaria.

I have alluded to these changes for two reasons : firstly, to show that as they demonstrate a nisus or its cessation in the ovaria and testes, one may fairly consider thc changes themselves as indicating the period when the concurrent atrophy or the excitement of the reproductive organs takes place; secondly, that we may be better able to trace the diseases directly or indirectly dependent thereon. To this last I shall refer again.

M. Quetelet has published in the ninth volume of the "Transactions of the Royal Academy of Brussels," some directions for the observation of periodic phenomena. These are arranged under the heads of -1 . Meteorology and "physique" of the earth. 2. The vegetable kingdom, noting the annual and diurnal periods, and giving a list of plants to be observed. 3. The animal kingdom. Now, the instructions under the last head appear to be incomplete. As, in giving these, M. Quetelet has been guided more by the views of Mr. de Selys, Longchamps, and M. Cantraine, than by his own judgment, he will, perhaps, the more readily permit me to offer some suggestions, which, if adopted, may render his and their plan more perfect, for I ought to state that philosophers in different parts of Europe have promised to adopt this proposed system of simultaneous observations.

1. I would suggest that the moults of all animals should be more extensively observed, and not those of birds exclusively. Thus, the arachnidæ, according to Audouin, cast their skin in spring, after the exclusion of the ova; the crustacea shed their shell as 
regularly as the stag his horns. Snakes change the whole of the epidermis every autumn, even the outer layer of the cornea is cast off. It does not appear that fishes moult, but they undergo other changes in the skin analogous to those observed in birds and mammals. Young sea-breams (chads) acquire the lateral spot only during the first autumn after they are spawned, when they are about half grown. The young of the whole of the genus salmo are striped, but the stripes disappear just as the spots and stripes in the young of the cervine and feline tribes of mammals, for the young of the lion and puma are as much marked, for a time, as those of the tiger and leopard.

2. The seasonal change in the colour, form, and other changes of the cutaneous appendages, might also be noted more extensively. The pectoral fins of the grayling are reddish about spawning time, and the male bull-trout is of a different colour at the same season. The white spots of the fallow-deer (cervus dama) disappear at the casting of the coat in autumn, and reappear in spring, but new hairs are not produced.

3. The mortality of animals might be observed. The period of moulting is always one of sickness, for the whole system is affected. Numbers of the common shrew are found dead in autumn, a mortality probably in some way connected with the seasonal change.

M. Quetelet notes the period when the green grasshopper first chirps as worthy of observation, but the changes in the voices of animals should be noted, or, at least, the song of birds. The cuckoo's note, for example, changes in $J$ une, when the ovaria begin to shrink.* In noting all these normal changes, adult animals should be carefully distinguished from the young, but especially in observing the moults of birds, as all birds moult in from one to three months after being incubated. The moulting of the sexual plumage should also be distinguished from the general moult. In noting the migratory movements the male animal should be distinguished from the female, as the two sexes differ considerably in their habits. There are some curious coincidences in periodic phenomena worth noting, as the departure of swifts, \&c., coinciding with the storms and meteors of August 10th-12th.

If we examine closely the annual changes in animals, we shall find that there are two distinct series, the one exoteric, the other

* This change has long been popularly observed. Shakspeare and Ben Johnson both allude to it; it has even become the burden of a popular rhyme :-

$$
\begin{aligned}
& \text { In flowing May, } \\
& \text { He sings all day ; } \\
& \text { In leafy June, } \\
& \text { He changes his tune: } \\
& \text { In ripe August, } \\
& \text { Go be must.-(Comaron Provir B.) }
\end{aligned}
$$

esoteric, but running into each other. The habits of insects are not guided by temperature solely. They, like our summer emigrants, seek winter quarters in autumn, long before the cold sets in, and even when the season is not so cold as it had been during the summer. Their revival in spring is also dependant upon something more than the mere sensation of warmth. Kirby and Spence (whose statements I quote) attribute these movements to instinct (Entomology, second edition, vol. ii., pp. 38 and 56); but it is plain they are analogous to the migratory movements of fishes, birds, and mammals. In many birds the vernal generative nisus is clearly esoteric, that is to say, like the re-appearance of insects, it is independent of meteorological changes; for the pairing of many birds takes place in February, a month much colder than October or November, when the generative functions cease. After this vernal period of activity the summer period of repose comes on, the ovaria shrink, and the sexual feathers fall off. Then another period of activity recurs, the sexual plumage re-appears, the reproductive functions are again performed; next the autumnal moult follows, and now all the feathers, together with the sexual, are cast off. Then comes the winter garb, and a change in the colour only of the feathers, and not in the feathers themselves. This is a period of repose, and is terminated by the vernal period of activity, when the sexual plumage and colours are superadded to the autumaal growth of feathers. Now, some of our birds of passage do not rear their second brood. Swifts, like nightingales, migrate to Southern Europe in August, for this purpose, but a solitary pair occasionally remains behind the rest, detained by some accidental circumstance, and then they will have a brood in September and migrate in October. Cuckoos are summer emigrants, but if kept in a cage they moult in autumn.

Does man undergo any changes of the kind described? that is to say, are the reproductive organs in him less active in winter and the beginning of summer-more active in spring and at the end of summer? and is there anything like a moult in autumn? Statistics show us that the greater number of births occur in December, February, and March, and the fewest in June, July, and August; consequently, the greatest number of conceptions would take place in August or September, May, and June, and the fewest in October, November, and December. In the following table, drawn up from Quetelet's data, the first column exhibits the number of births in the rural districts of the Low Countries, from 1815 to 1826, inclusive, and the second, the ratio. *

* The statistical return of births in the Report of the Registar-General are for the four quarters of the year only, the popular division, and, of course, are not available here. 


\begin{tabular}{|c|c|c|}
\hline & & \\
\hline צטיצ & 1 & \\
\hline oruary & & \\
\hline March & & \\
\hline A & & \\
\hline & 13 & \\
\hline$\ldots$ & 12 & \\
\hline & 12 & \\
\hline & & \\
\hline & 14 & 95 \\
\hline & 14 & \\
\hline & & \\
\hline & 86 & 7 \\
\hline
\end{tabular}

We might also expect abortions and uterine profluvia to be more frequent in spring, and this $a$ priori inference the general statements of various writers seem to bear out. It is a popular notion that the sexual feelings are strongest in spring and least ardent in autumn-an old idea, since Rufus, a Greek writer, quoted by both Oribasius and Etius, has left it on record.

The characteristics of the cutaneous appendages in man are not sufficiently striking to decide, without close observation, whether there be an autumnal moult or not. "Spring and fall" have long been popularly known as the seasons in which cutaneous eruptions are most apt to appear; and the habits of some of the exanthemata render it probable that there is a determination to the skin at these seasons. In those diseases in which the horny structures of the skin are unusually developed, as ichthyosis and pellagra, a seasonal change is experienced. The "porcupine man," as he was called (whose history is recorded in the early volumes of the "Philosophical Transactions"), and his descendants, appear to have all cast their scales in autumn. In pellagra, according to Dr. Holland's observations, the cutaneous affection remits in autumn and recurs with increased severity in spring.

It is difficult to class the diseases which may arise secondarily from the exaltation or diminution of function in the ovaria and testes. The brain may sympathise with them, and cerebral affections result; or the functions of the kidneys may be disturbed, since the anatomical and physiological relations of the two sets of organs are very intimate. Thus, the fatality of epidemic exanthemata, as rubeola and scarlatina, may be infuenced by the physiological condition of the kidneys. Thus, also, a variety of neuroses, particularly the urinary neuroses, gout in all its forms, rheumatism, hysteria, hypochondriasis, \&c., may be developed. I must, however, refer to my published work in proof that these diseases, independently of theory, are more apt to recur at spring and autumn than at any other times.

The diseases which arise at particular periods, from exoteric causes, may be arranged in two classes. The hygrometric and thermometric changes of the year must neces. sarily induce changes in the density of the atmosphere, and this change in density will be equal to an increase or diminution in the excretion and imbibing power of the lungs. As, at each inspiration, less oxygen will be taken into the lungs in summer than in winter, less carbon will be excreted, and hence the necessity for a vicarious or com. plementary action of the liver during the hot months. In this way we can readily explain why bilious diseases are more prevalent in the hot months and in hot climates. The perspiratory organs of the skin are also more active in summer, and the urinary secretion proportionately diminished. Various dis. eases are directly consequent on these and similar changes in the seasons, and constitute one of the two classes referred to. The other class will comprise those for the most part dependent upon causes properly terres. trial, as marsh and jungle fevers, although these are doubtless connected with the phy. siological changes just alluded to.*

Of course the action of remedies would vary under all these circumstances-a gene. ral principle of the highest importance, although $I$ pass it thus cursorily. I cannot close this part of my paper better than by the summary of seasonal diseases left by Hippocrates:-

"Diseases of every kind may arise in any season of the year; others, however, in. crease and are excited only in particular seasons.

"6 In spring, insanity, melancholy, epilepsy, hæmorthages, anginæ, catarrhs, hoarseness, coughs, lepra, impetigines, vitiligines, pustules, numerous ulcers, tubercles, and pains in the joints.

"Iu summer, some of these, together with continued and ardent fevers, many tertians and quartans, vomiting, diarrhoea, lippitudo, otalgia, ulcers in the month, genitalium, putredines, and sweats.

"In autumn, the fevers of summer, both quartans and erratic diseases of the spleen, anasarca, tabes, stillicidia urinæ, diarrhoea and tenesmus, sciatica, anginæ, shortness of breath, volvuli, epileptic fits, insanity, melancholy.

"In winter, pleurisies, inflammation of the lungs, lethargies, catarths, hoarseness,

* In his late communication to the Statis tical Society, on the Influence of the Seasons, Dr. Guy distinguishes very distinctly be. tween these two classes of diseases. It is manifestly of importance that the distinction should be borne in mind. Dr. Guy will see, however, that I am inclined to differ with him as to the greater prevalence of the sexual instinct during the hottest months. Not having yet seen his original paper, I am unacquainted with the diseases which, in his opinion, form a measure of the activity of the sexual passion, and, of course, am unable to point out the grounds of difference. 
coughs, pain in the chest, sides, and loins, (for exactness is absolutely necessary) when headaches, vertigo, apoplexy." (Aph., lib. he is informed that, firstly, the subject must iii., S. $x i x-x x$ iii.)

This was written above two thousand years ago, and probably a better summary of the seasonal diseases of Greece could not now be given.

I may here remark, as an answer to some private correspondents, that the papers I have communicated from time to time to THE LANCET are rather presented to the public as "memoires pour servire" than as finished productions. They are mainly intended to form the outline of vital proleptics, to incite the collection of materials for the complete structure scattered through various branches of science, and particularly to point out what observations are wanting to connect and cement these materials. With special reference to the last object $I$ would observe that M. Schwann, a corresponding member of the Royal Academy of Brussels, has published in the Transactions of that academy (tom. ix.) a set of instructions for the observation of the periodic phenomena of man, as a sequel to the instructions of $M$. Quetelet, before referred to. It appears to me that those instructions are imperfect, and that M. Schwann has neither been fully acquainted with what it is necessary to observe, nor with what can be observed. $\mathrm{He}$ justly remarks, that rutting, or " the heat," migration, moulting, and hybernation, are the principal periodic phenomena to be observed in animals, but declares positively that if we seek for analogous phenomena in mankind we cannot find them. Now, this is both an error and an abandonment of the greatest and most important class of phenomena to be observed,-the class connected with esoteric periodic changes, - of the daily, weekly, monthly, or seasonal recurrence of which, as shown in my current paper and the preceding, M. Schwann appears to have no idea whatever. Unless, however, these are correctly observed in all their relations, the mere observation of meteorological or exoteric pathological changes will lead to little better than inexplicable anomalies. It will be like prosecuting the study of physiology by pathological facts exclusively. But, indeed, we already know, in a great degree, what M. Schwann has laid down under his first head as proper to be observed, and Mr. Farr alone could complete our knowledge. In the second head of his paper M. Schwann gives instructions for observing the phenomena which occur at certain periods of life, including, of course, the septennial periods. The object to be obtained and its importance are well stated,-not so the means of its attainment. The first and principal, according to M. Schwann, is to weigh and measure the different viscera as well as the general dimensions of the body. The anatomist, however, will easily appreciate the difficulty of fulfilling exactly the necessary conditions

No. 1051. be a healthy individual, and necessarily a person who has been accidentally killed; then, again, he must not be a fat subject, as fat would add to the weight and size of organs; next, every viscus in every subject must be properly prepared for weighing and measuring,- the cerebrum and cerebellum, the medulla oblongata and medulla spinalis, the abdominal and thoracic viscera, the thyroid body, the supra-renal capsules, the salivary glands, and the weight of the muscle, less the weight of the bones "apres la maceration." All this is very good, but the plain truth is, such observations on an extended scale (and they must be on an extended scale to be useful) are, in one word, impossible, and it is scarcely uecessary to add that if possible they would be of little real (or what is the same thing) practical value, without an equally extensive knowledge of periodicity in the functions of organs. The object aimed at would, indeed, be better at. tained by observing the latter, because the degree of development of organs may in general be expressed by their functional activity. One advantage that practical medicine would derive would also be much greater; for the diseases that can be cured or alleviated are either functional or must be treated with reference to function, and that even when structural.

Now, I should regret if, in making these suggestions to M.Quetelet and his coadjutors, I should be thought to detract from the merits of those gentlemen. Nothing I could say would add to the well-deserved reputation of $\mathbf{M}$. Quetelet, and if there be those imperfections in the instructions which I have pointed out, it is manifest that they may arise rather from the immense extent of the subject than from individual incapacity or negligence. The materials are so scattered, and first principles so imperfect, that no one mind, however happily constituted, could grasp the whole. The attempt now made by the Belgian academicians to secure the systematic and philosophic observation of periodic phenomena is, without doubt, an excellent beginning.

York, October 14, 1843.

Borls.-You cannot disperse them, even if you ought, you may try, therefore, to bring the boil forward by steaming; but you had better cover it with plaster, and attend to its source, and prevent others, by attention to the stomach, by an emetic and alterative pill, and bitter infusion with alkaline solutions. When it looks ill, and exhibits a mass of corrupted cellular membrane, it should be dressed with digestive ointment and poulticed. To correct the disposition to them, after considering the state of the intestinal canal, give antimorials, and order the warm bath.-Sir Charles Bell. 